\title{
DID THE INTRODUCTION OF A MINIMALLY INVASIVE TECHNIQUE CHANGE THE INCIDENCE OF ATRIAL FIBRILLATION AFTER SINGLE INTERNAL THORACIC ARTERY-LEFT ANTERIOR DESCENDING ARTERY GRAFTING?
}

Xavier M. Mueller, MD

Hendrik T. Tevaearai, MD

Patrick Ruchat, MD

Frank Stumpe, MD

Ludwig K. von Segesser, MD

For related editorial, see p. 638.
Objective: Atrial fibrillation after coronary artery bypass operations remains frequent and increases morbidity, as well as resource use. Its cause remains unclear. The introduction of a minimally invasive technique provides an opportunity to evaluate the effect of intraoperative factors, such as cardiopulmonary bypass, global myocardial ischemia, and myocardial protection technique, on the occurrence of this arrhythmia.

Methods: All the patients undergoing isolated left internal thoracic artery-left anterior descending artery grafting between January 1994 and December 1999 were reviewed. Twenty possible risk factors for postoperative atrial fibrillation, including the choice of operative technique-minimally invasive technique was introduced in January 1997-were entered into univariate and multivariable logistic regression analysis.

Results: Postoperative atrial fibrillation occurred in 36 (20\%) of 183 patients. On univariate analysis, age $(P<.001)$ and a history of supraventricular arrhythmia $(P<.001)$ were found to be risk factors. In particular, $15(22 \%)$ of 69 patients operated on with the minimally invasive technique had postoperative atrial fibrillation versus $21(18 \%)$ of 114 in the standard group $(P=.58)$. On multivariable analysis, including the operative technique, the same variables $(P=.001$ and .01 , respectively) were identified as independent risk factors.

Conclusions: The introduction of a minimally invasive technique for coronary artery bypass operations did not reduce the occurrence of postoperative atrial fibrillation in this study population. This suggests that prophylactic measures to reduce this arrhythmia should be focused on factors unrelated to cardiopulmonary bypass or myocardial preservation technique. (J Thorac Cardiovasc Surg 2001;121:683-8)
$\mathrm{P}$ ostoperative atrial fibrillation (AF) after coronary artery bypass grafting (CABG) is common, with a reported prevalence of $20 \%$ to $40 \% .^{1-4}$ Although this arrhythmia is usually benign, it may result in hemodynamic compromise, subjective discomfort and anxiety, thromboemboli, lengthened hospital stay, need for posthospital medication, and increased total cost of medical care. Moreover, treatment of AF may be associated with potentially harmful side effects.

From the Clinic for Cardiovascular Surgery, CHUV (Centre Hospitalier Universitaire Vaudois), CH-1011 Lausanne, Switzerland.

Copyright (c) 2001 by The American Association for Thoracic Surgery

$0022-5223 / 2001 \$ 35.00+0 \quad \mathbf{1 2 / 1 / 1 1 2 5 2 9}$

doi: $10.1067 / \mathrm{mtc} .2001 .112529$
Although AF after CABG has been extensively studied, its pathophysiologic mechanism remains unclear. Among others, it has been related to factors directly linked with the operative procedure: cardiopulmonary bypass (CPB), atrial cannulation technique, myocardial ischemia, and myocardial preservation technique. ${ }^{4-6}$

Minimally invasive CABG obviates the need for CPB and cardioplegic arrest. Therefore, it provides a unique opportunity to analyze the effect of these factors on the occurrence of postoperative AF. Notably, the advocates of this technique have postulated that one potential benefit of this approach would be a reduction in postoperative atrial arrhythmias. To minimize the influence of factors related to the extent of coronary artery disease, especially the involvement of the right coronary artery, ${ }^{7}$ and factors linked with the extent of the revasculariza- 
Table I. Preoperative variables

\begin{tabular}{lccc}
\hline & SR group $(n=147)$ & AF group $(n=36)$ & P value \\
\hline Age $(\mathrm{y})$ & $58.7 \pm 8.4$ & $65.7 \pm 7$ & $<.001$ \\
Male sex & $79 \%(116)$ & $83 \%(30)$ & .55 \\
Diabetes & $14 \%(21)$ & $14 \%(5)$ & .95 \\
Hypertension & $47 \%(69)$ & $50 \%(18)$ & .74 \\
Creatinine $\geq 120 \mu \mathrm{mol} / \mathrm{L}$ & $6.1 \%(9)$ & $5.6 \%(2)$ & .89 \\
COPD & $8.8 \%(13)$ & $8.3 \%(3)$ & .92 \\
History of smoking & $53 \%(78)$ & $56 \%(20)$ & .78 \\
History of supraventricular arrhythmias & $2.7 \%(4)$ & $17 \%(6)$ & $<.001$ \\
Post-MI & $31 \%(45)$ & $33 \%(12)$ & .75 \\
Ejection fraction & $53.7 \% \pm 3.8 \%$ & .51 \\
Preoperative calcium antagonist & $42 \%(62)$ & $54.1 \% \pm 2.8 \%$ & .58 \\
Preoperative $\beta$-blockers & $61 \%(90)$ & $47 \%(17)$ & .36 \\
Preoperative digitalis & $1.4 \%(2)$ & $69 \%(25)$ & .12 \\
Unstable angina & $8.1 \%(12)$ & $5.6 \%(2)$ & .13
\end{tabular}

Values in parentheses are actual numbers of patients. SR, Sinus rhythm; COPD, chronic obstructive pulmonary disease; $M I$, myocardial infarction.

Table II. Intraoperative and postoperative variables

\begin{tabular}{lccc}
\hline & SR group $(n=147)$ & AF group $(n=36)$ & P value \\
\hline Minimally invasive technique & $37 \%(54)$ & $42 \%(15)$ & .58 \\
Lowest systemic temperature $\left({ }^{\circ} \mathrm{C}\right)$ & $34.47 \pm 1.33$ & $34.2 \pm 1.35$ & .3 \\
Return to OR & $4.1 \%(6)$ & $2.7 \%(1)$ & .6 \\
Myocardial infarction & $1.4 \%(2)$ & $2.7 \%(1)$ & .54 \\
Inotropic support & $2 \%(3)$ & $2.7 \%(1)$ & .55 \\
Ventilation $>24 \mathrm{~h}$ & $5.4 \%(8)$ & $5.5 \%(2)$ & .98 \\
\hline
\end{tabular}

Values in parentheses are actual numbers of patients. $S R$, Sinus rhythm; $O R$, operating room.

Table III. Multivariable predictors of AF

\begin{tabular}{llll}
\hline & P value & Odds ratio & $95 \%$ CI \\
\hline Age & .001 & 1.08 & $1.03-1.13$ \\
History of supraventricular arrhythmia & .01 & 4.63 & $1.37-15.62$ \\
Operative technique & .81 & 0.9 & $0.41-2$
\end{tabular}

The corresponding equation was as follows: Logit $P=-6.256+0.0762$ (age) +1.533 (history of supraventricular arrhythmia) -0.0996 (operative technique).

tion procedure, we analyzed the effect of the introduction of minimally invasive techniques on the occurrence of postoperative $\mathrm{AF}$ in a patient population undergoing isolated grafting of the left internal thoracic artery (LITA) to the left anterior descending artery (LAD).

\section{Patients and methods}

Study patients. The study population consisted of all patients undergoing isolated LITA grafting onto the LAD at our institution over a 6-year period from January 1994 through December 1999. Minimally invasive technique was introduced in January 1997. The choice of the surgical tech- nique varied initially according to the surgeon's preference, but the minimally invasive technique eventually became the routine procedure. Patients with chronic AF, those with right coronary artery disease, and those undergoing a redo operation were excluded from the study. No patient had significant valve disease necessitating surgical intervention. Information regarding each patient's medical history, operative procedure, and postoperative course were prospectively recorded and were entered into a database.

Surgical technique. Standard CABG operations were performed, with the patient undergoing $\mathrm{CPB}$ with moderate hemodilution and moderate hypothermia $\left(28^{\circ} \mathrm{C}\right)$. Standard cannulation was used with a double-stage venous cannula inserted through the right auricular appendix into the inferior 
Table IV. Preoperative variables: Minimally invasive versus standard technique

\begin{tabular}{lccc}
\hline & Standard technique $(n=114)$ & Minimally invasive technique $(n=69)$ & P value \\
\hline Age $(y)$ & $59.3 \pm 8.3$ & $61.5 \pm 8.6$ & .14 \\
Male sex & $78 \%(89)$ & $83 \%(57)$ & .54 \\
Diabetes & $15 \%(17)$ & $13 \%(9)$ & .72 \\
Hypertension & $47 \%(54)$ & $48 \%(33)$ & .95 \\
Creatinine $\geq 120 \mu \mathrm{mol} / \mathrm{L}$ & $6.1 \%(7)$ & $5.8 \%(4)$ & .99 \\
COPD & $9.6 \%(11)$ & $7.2(5)$ & .54 \\
History of smoking & $53 \%(60)$ & $55 \%(38)$ & .1 \\
History of supraventricular arrhythmias & $6.1 \%(7)$ & $4.3 \%(3)$ & .74 \\
Post-MI & $27 \%(31)$ & $38 \%(26)$ & .14 \\
Ejection fraction & $54.1 \% \pm 2.8 \%$ & $53.3 \% \pm 4.5 \%$ & .11 \\
Preoperative calcium antagonist & $46 \%(52)$ & $39 \%(27)$ & .27 \\
Preoperative $\beta$-blockers & $59 \%(67)$ & $70 \%(48)$ & .14 \\
Preoperative digitalis & $2.6 \%(3)$ & $1.4 \%(1)$ & .99 \\
Unstable angina & $9.6 \%(11)$ & $10 \%(7)$ & .93 \\
\hline
\end{tabular}

Values in parentheses are actual numbers of patients. COPD, Chronic obstructive pulmonary disease; $M I$, myocardial infarction.

vena cava. Cold crystalloid cardioplegia and topical pericardial cooling were used for myocardial protection. The median sternotomy was closed, leaving in place 2 mediastinal tubes and a left pleural drain.

The minimally invasive direct procedure consisted of grafting the LITA to the LAD either directly (55 patients) or by interposing a segment of epigastric artery (14 patients), as described by Cohn and colleagues. ${ }^{8}$ The chest was opened through an incision in the fourth or fifth intercostal space. The patient was heparinized (100 IU/kg) after the conduit harvesting. The pericardium was incised transversely, and traction sutures were applied to its edge. A snare of 4-0 Prolene suture (Ethicon GmbH and Co KG, Norderstedt, Germany) was applied proximally and distally to the site elected for the anastomosis. Short-acting calcium channel blockers were used to reduce heart rate when necessary. Anastomosis of the LITA to the LAD was accomplished with the help of a stabilizer. At completion of the procedure, a left pleural drain was left in place.

Clinical evaluation. All patients had continuous cardiac rhythm monitoring for 72 hours. During this period, AF identified on the monitor was confirmed by a recording of a rhythm strip or a 12-lead electrocardiogram. After cessation of continuous monitoring, arrhythmias were identified by means of twice daily pulse palpation or clinical signs and symptoms and confirmed by means of a 12-lead electrocardiogram. In all patients a routine electrocardiogram was performed on the seventh postoperative day.

The relation of AF to 20 perioperative variables was evaluated. Preoperative variables included age, sex, presence of diabetes, hypertension, creatinine level of $120 \mu \mathrm{mol} / \mathrm{L}$ or greater, smoking, and chronic obstructive pulmonary disease; a medical history of supraventricular arrhythmia and myocardial infarction; unstable angina; and ejection fraction. Preoperative use of digitalis, calcium channel blocking agents, and $\beta$-blocking agents at the time of admission was also evaluated. Potential intraoperative predictors of postop- erative $\mathrm{AF}$ included the choice of the operative technique (standard vs minimally invasive) and the lowest systemic temperature achieved. The following postoperative factors were analyzed: reoperation for hemorrhage; myocardial infarction; the need for inotrope support; and ventilation of more than 24 hours.

Because patients were not randomized with regard to the surgical technique, preoperative characteristics of patients operated on with standard and minimally invasive techniques were compared.

Statistics. All data were entered into a spreadsheet software program (Microsoft Excel 4) and analyzed with Sigmastat (SPSS, Inc, Chicago, Ill). Univariate analysis of the influence of categoric variables on postoperative occurrence of AF was performed with a $\chi^{2}$ test. Continuous data were analyzed with logistic regression. Independent predictors of AF were determined by a multivariable logistic regression analysis that included the variables identified as significant on univariate analysis, as well as the operative technique (minimally invasive vs standard). Because patients were not randomly assigned to undergo either the standard or minimally invasive techniques, preoperative variables of both groups underwent univariate analysis.

\section{Results}

Postoperative AF occurred in 36 (20\%) of 183 patients a mean of 2.4 days after the $\mathrm{CABG}$ operations (range, 1-5 days). Table I shows the preoperative baseline characteristics for each group with the appropriate univariate $P$ values. Patients with AF were significantly older and presented more frequently with a history of supraventricular arrhythmia. The intraoperative and postoperative variables are summarized in Table II, and none of these variables resulted in a significant difference between the 2 groups. 
Multivariable logistic regression analysis, including the significant variables of the univariate analysis, as well as the operative technique, identified age and a history of supraventricular arrhythmia as the independent correlates for AF. The odds ratio and $P$ value for each multivariable predictor are shown in Table III.

Importantly, none of the preoperative variables differed significantly when the standard and minimally invasive groups were compared by means of univariate analysis (Table IV). In the minimally invasive group, $15(22 \%)$ of 69 patients had postoperative AF versus 21 $(18 \%)$ of 114 in the standard group $(P=.58)$.

\section{Discussion}

Despite extensive evaluation, postoperative $\mathrm{AF}$ remains a common event after CABG. Because of its potential for hemodynamic compromise and thromboembolic complications, as well as its effect on resource use, this problem remains a concern for the postoperative course of an ever-aging patient population at increased risk for this arrhythmia. The results of this prospective study analyzing patients undergoing isolated LITA-LAD grafting show that the introduction of a minimally invasive technique did not alter the occurrence of this arrhythmia. However, in keeping with the results of the literature, age and a history of supraventricular arrrhythmia were identified as independent risk factors. Age has consistently been demonstrated to be the most important risk factor for postoperative AF. ${ }^{1-4}$ This association has been explained by the age-related structural changes in the atrium, such as dilatation, muscle atrophy, decreased conduction tissue, and fibrosis..$^{9,10}$ A history of supraventricular arrhythmias is too commonly referred to as a risk factor, ${ }^{4,11,12}$ suggesting a predisposing anatomic ground, electrophysiologic ground, or both.

CPB and myocardial preservation do not appear to have any effect on the prevalence of postoperative AF in this patient population. To the best of our knowledge, there are no clear objective data in the literature supporting the commonly mentioned assumption that CPB (with its systemic inflammatory response), myocardial ischemia, and method of myocardial preservation are proarrhythmic factors in adults undergoing coronary operations. The results of experiments testing the hypothesis that improved right atrial cooling may reduce the occurrence of supraventricular arrhythmias are conflicting. ${ }^{6,13}$ In a series of patients operated on with cold cardioplegia or intermittent ischemic arrest, the occurrence of postoperative AF was similar, irrespective of the technique of myocardial preservation. ${ }^{14}$ Bicaval cannulation technique has been reported to have a significant effect in one multicenter prospective study involving 2048 patients undergoing $\mathrm{CABG}$ without concurrent valvular operations. ${ }^{4}$ However, the proportion of patients with bicaval venous cannulation was small (214/2048 [10.4\%]), and the detection of AF relied on only 2 electrocardiograms obtained during the first 10 postoperative days. Considering the similar prevalence of postoperative $\mathrm{AF}$ in patients with standard $\mathrm{CPB}$ and in those operated on with a minimally invasive technique, mechanisms common to both types of surgical techniques and specific to cardiac operations should be looked for. The opening of the pericardium with local inflammatory response appears to be a potential explanation. One study found a lower occurrence of AF after transmyocardial laser revascularization in comparison with standard and minimally invasive revascularization. ${ }^{15}$ The authors argued that most of the patients undergoing the laser procedure had undergone previous surgical revascularization and that the adherence would have protected the atria from being exposed directly during the laser procedure performed through a limited left anterior thoracotomy. Moreover, a relationship between significant pericardial effusion and AF has been reported in patients undergoing valve replacement. ${ }^{16}$ In lung resection operations a higher prevalence of supraventricular arrhythmias has been found after pneumonectomy in comparison with lobectomy or wedge resection, and the occurrence of $23 \%$ to $24 \%{ }^{17,18}$ is similar to that of the present series. Krowka and colleagues, ${ }^{19}$ in a study focusing on supraventricular tachyarrhythmias after pneumonectomy, found a higher prevalence in patients undergoing intrapericardial dissection. All these findings further argue for the potential importance of local inflammation. Myocardial ischemia-reperfusion linked with the construction of the coronary anastomosis is another mechanism common to standard and minimally invasive revascularization. However, although cytokine levels have been shown to be correlated with the duration of global myocardial ischemia after $\mathrm{CPB},{ }^{20,21}$ they are significantly lowered with a minimally invasive technique. ${ }^{22}$ Furthermore, transient ischemias occurring in other clinical conditions, such as unstable angina pectoris or successful thrombolysis of acute myocardial infarction, have not been associated with an increased prevalence of AF. These findings would rather argue against an influence of transient ischemia in our patient population, keeping in mind that in the minimally invasive technique a limited ventricular area of the LAD territory is involved, which would preserve the atria from the ischemic process. 
Three other works have analyzed AF after minimally invasive $\mathrm{CABG}$. Cohn and colleagues ${ }^{23}$ compared the prevalence of AF after standard cardiac operations and minimally invasive cardiac operations through an anterior thoracotomy in 110 patients matched by age and date of operation, with an occurrence of $20 \%$ and $24 \%$, respectively $(P=.6)$. Both groups differed, however, by the extent of revascularization, with a mean number of distal anastomoses of $3.6 \pm 1.1$ and $1.1 \pm 0.48$, respectively. Saatvedt and colleagues ${ }^{15}$ found no differences between 2 groups of 19 patients operated on with standard or off-pump techniques through a median sternotomy, with an occurrence of $36 \%$ and $37 \%$, respectively. This study involved reoperations, and the mean number of distal anastomoses was 3.6 and 1.9, respectively. Siebert and colleagues ${ }^{24}$ analyzed 87 patients, 48 of whom were operated on without CPB, 24 of whom were operated on using off-pump CABG through a sternotomy, and 24 of whom were operated on using the minimally invasive technique through an anterior thoracotomy. In 39 patients a standard operation with CPB was performed. AF occurred in $25 \%$, $29 \%$, and $18 \%$, respectively. The difference had no statistical significance. All the patients were treated with $\beta$-blockers before intervention, and the treatment was continued immediately after the operation. The number of distal anastomoses was not mentioned. Overall, although differently designed, these studies are in keeping with our findings.

Importantly, this study prospectively addresses a specific patient group among the CABG population. Patients with multiple CABGs present a more extensive disease, often with involvement of the right coronary artery, which has been shown to be a significant determinant of postoperative AF. ${ }^{7}$ This difference could explain our prevalence of AF, which is in the lower range of that reported in the literature. ${ }^{1-4}$ Taking into account this specific design, our study shows that even with limited coronary artery disease, AF is still significantly more frequent than after noncardiac operations and that in this group of patients CPB and myocardial preservation techniques are unlikely to be determinant.

One limitation of this analysis lies in the absence of randomization to either the standard or minimally invasive technique. On the one hand, the minimally invasive technique was introduced in the course of the study period, and on the other hand, its choice was subject to the surgeon's preference, although it became the routine procedure with time. However, univariate analysis of preoperative characteristics did not show any significant differences between both groups, therefore minimizing this limitation. Another limitation is the small population investigated, which makes unequivocal conclusion impossible. If one were setting up a prospective study to identify at least a $25 \%$ reduction in $\mathrm{AF}$ from $20 \%$ to $15 \%$ between the standard and minimally invasive techniques, then nearly 2000 patients would be needed to have an $80 \%$ chance of detecting such a difference at a significance level of .05 . The organization and the completion of such a study would require multi-institutional involvement and a considerable investment. The alternative is a meta-analysis of several limited series, the statistical power of which is also questionable. Therefore, when considering that all the other series comparing the occurrence of AF between both techniques uniformly report the absence of significant differences, we have to accept that the minimally invasive technique is responsible for an increased incidence of AF per se.

With these limitations in mind, this study could not demonstrate any reduction of the incidence of postoperative $\mathrm{AF}$ with the introduction of a minimally invasive technique for CABG operations, suggesting that efforts should be focused on factors other than CPB and cardioplegic arrest to reduce this frequent arrhythmia.

Received for publication June 7, 2000; revisions requested Aug 24, 2000; revisions received Sept 14, 2000; accepted for publication Oct 27, 2000.

Address for reprints: X. Mueller, MD, Clinic for Cardiovascular Surgery, CHUV (Centre Hospitalier Universitaire Vaudois), CH-1011 Lausanne, Switzerland (E-mail: xavier.mueller@chuv.hospvd.ch).

\section{REFERENCES}

1. Leitch JW, Thomson D, Baird DK, Harris PJ. The importance of age as a predictor of atrial fibrillation after coronary artery bypass grafting. J Thorac Cardiovasc Surg 1990;100:338-42.

2. Cressler LL, Scheussler RB, Rosenbloom M, Cox JL. Hazards of postoperative atrial arrhythmias. Ann Thorac Surg 1993;56: $539-49$.

3. Aranki SF, Shaw DP, Adams DH, Rizzo RJ, Couper GS, VanderVliet M, et al. Predictors of atrial fibrillation after coronary artery surgery: current trends and impact on hospital resources. Circulation 1996;94:390-7.

4. Mathew JP, Parks R, Saviano JS, Friedman AS, Koch C, Mangano DT, et al. Atrial fibrillation following coronary artery bypass graft surgery: predictors, outcomes and resource utilization. JAMA 1996;276:3000-6.

5. Chen X, Newman M, Rosenfeldt FL. Internal cardiac cooling improves atrial preservation: electrophysiological and biochemical assessment. Ann Thorac Surg 1988;46:406-11.

6. Tchervenkov CI, Wynands JE, Symes JF, Malcolm ID, Dobell ARC, Morin JE. Persistent atrial activity during cardioplegic arrest: a possible factor in the etiology of postoperative supraventricular tachyarrhythmias. Ann Thorac Surg 1983;36:437-42.

7. Mendes LA, Connelly GP, McKenney PA, Podrid J, Cupples A, 
Shemin RJ, et al. Right coronary artery stenosis: an independent predictor of atrial fibrillation after coronary artery bypass surgery. J Am Coll Cardiol 1995;25:198-202.

8. Cohn WE, Suen HC, Wientraub RM, Johnson RG. The "H" graft: an alternative approach for performing minimally invasive direct coronary artery bypass. J Thorac Cardiovasc Surg 1998;115:148-51.

9. Kitzman DW, Edwards WD. Age-related changes in the anatomy of the normal human heart. J Gerontol 1990;45:M33-9.

10. Lie JT, Hammond PI. Pathology of the senescent heart: anatomic observations on 237 autopsy studies of patients of 90 to 105 years old. Mayo Clin Proc 1988;63:552-64.

11. Hashimoto K, Ilstrup DM, Schaff HV. Influence of clinical and hemodynamic variables on risk of supraventricular tachycardia after coronary artery bypass. J Thorac Cardiovasc Surg 1991;101:56-65.

12. Ducceschi V, D'Andrea A, Liccardo B, Alfieri A, Sarubbi B, De Feo M, et al. Perioperative clinical predictors of atrial fibrillation occurrence following coronary artery surgery. Eur J Cardiothorac Surg 1999;16:435-9.

13. Sato S, Yamauchi S, Schluessler RB, Boineau JP, Matsunaga Y, Cox JL. The effect of augmented atrial hypothermia on atrial refractory period, conduction, and atrial flutter/fibrillation in the canine heart. J Thorac Cardiovasc Surg 1992;104:297-306.

14. Pattison CW, Dimitri WR, Williams BT. Dysrhythmias following coronary artery surgery: a comparison between cold cardioplegic and intermittent ischemic arrest $\left(32^{\circ} \mathrm{C}\right)$ with the effect of right coronary endarterectomy. J Cadiovasc Surg 1988;29:601-5.

15. Saatvedt K, Fiane AE, Sellevold O, Nordstrand K. Is atrial fibrillation caused by extracorporeal circulation? Ann Thorac Surg 1999;68:931-3

16. Chidambaram M, Akthar MJ, al-Nozha M, al-Saddique A.
Relationship of atrial fibrillation to significant pericardial effusion in valve-replacement patients. Thorac Cardiovasc Surg 1992;40:70-3.

17. Von Knorring J, Lapäntalo M, Lindgren L, Lindfors O. Cardiac arrhythmias and myocardial ischemia after thoracotomy for lung cancer. Ann Thorac Surg 1992;53:642-7.

18. Dyszkiewicz W, Skrzypczak M. Atrial fibrillation after surgery of the lung: clinical analysis of risk factors. Eur J Cardiothorac Surg 1998;13:625-8.

19. Krowka MJ, Pairolero PC, Trastek VF, Payne WS, Bernatz PE. Cardiac dysrhythmia following pneumonectomy: clinical correlates and prognostic significance. Chest 1987;91:490-5.

20. Hennein HA, Ebba H, Rodriguez JL, Merrick SH, Keith FM, Bronstein $\mathrm{MH}$, et al. Relationship of the proinflammatory cytokines to myocardial ischemia and dysfunction after uncomplicated coronary revascularization. J Thorac Cardiovasc Surg 1994;108:626-35.

21. Wan S, Marchant A, DeSmet JM, Antoine M, Zhang H, Vachiery $\mathrm{JL}$, et al. Human cytokine responses to cardiac transplantation and coronary artery bypass grafting. J Thorac Cardiovasc Surg 1996;111:469-77.

22. Strüber M, Cremer JT, Gohrbandt B, Hagle C, Jankowski M, Völker B, et al. Human cytokine responses to coronary artery bypass grafting with and without cardiopulmonary bypass. Ann Thorac Surg 1999;68:1330-5.

23. Cohn WE, Sirois CA, Johnson RG. Atrial fibrillation after minimally invasive coronary artery bypass grafting: a retrospective, matched study. J Thorac Cardiovasc Surg 1999;117:298-301.

24. Siebert J, Rogowski J, Jagielak D, Anisimowicz L, Lango R, Narkiewicz M. Atrial fibrillation after coronary artery bypass grafting without cardiopulmonary bypass. Eur J Cardiothorac Surg 2000;17:520-3.

\section{Authoritative}

The Journal of Thoracic and Cardiovascular Surgery is the most frequently cited thoracic/cardiovascular surgery journal in the Science Citation Index. An article in JTCVS is sited on average almost twice as often as those in the closest cardiothoracic journal. 